\title{
Re: Ultrasound Guided Percutaneous Nephrostomy for Obstructive Uropathy in Benign and Malignant Diseases
}

\author{
G. Sood, A. Sood, A. Jindal, D.K. Verma, D.S. Dhiman \\ Department of Surgery, Indira Gandhi Medical College Shimla H.P., India.
}

Int Braz J Urol, 32: 281-6, 2006

To the Editor:

This article raises several concerns in my view as an urologist. There is no doubt, that ultrasound guided percutaneous nephrostomy has an established place in the daily clinical practice of our department. So, why published an article on recent experiences? Maybe to remind urologists not to neglect this very important field. It has to be noted, that this paper is present by a group of surgeons and radiologists from India, not by urologists!

As being trained by Ferdinand Eisenberger and Peter Alken, from Germany, percutaneous nephrostomy has become a daily routine performed by ourselves. I was happy to learn the free-hand puncture technique under ultrasonic guidance by Peter Alken and it is of course the standard in my department: Not only for release of obstruction in emergency cases as pointed out by the authors, but also as the first step during percutaneous nephrolithotomy.
This situation is different from centers in United Kingdom, United States or Austria, where the interventional radiologist places the nephrostomy needle. I am convinced, that particularly adequate training in diagnostic and therapeutic ultrasound should be of utmost importance for every urologist. Based on this, the puncture of a dilated collecting system represents the next logical step.

Of course, the placement of the nephrostomy has to be performed under fluoroscopic guidance and again preferably done by the urologist. If the department does not have an own X-ray unit (i.e. Siemens Access), new multifunctional lithotripters are ideal to be used for these procedures like for placement of ureteral stents.

In conclusion, this article should awake us in trying to do our best in training of the diagnostic and therapeutic use of renal ultrasound.

Respectfully,

Dr. Jens Rassweiler Chair of Urology, SLK Kliniken Heilbronn University of Heidelberg

Heilbronn, Germany

E-mail: jens.rassweiler@klinikum-heilbronn.de 